\title{
Tuning Stability of Coiled-Coil Heterotrimers by Selection of Steric Matching Partners
}

\author{
Philip Travisano and Alan J. Kennan* \\ Department of Chemistry, Colorado State University Fort Collins, Colorado 80523
}

\section{Supporting Information:}

Peptide Synthesis. Amino acids (including cyclohexylalanine) were obtained from NovaBiochem (San Diego). Peptides were prepared according to the in situ neutralization protocol developed by Kent. ${ }^{1}$ Each peptide was purified by reverse-phase HPLC (C-18 column, solvent $\mathrm{A}$ : $1 \% \mathrm{CH}_{3} \mathrm{CN}$ in $\mathrm{H}_{2} \mathrm{O}, 0.1 \%$ (v/v) $\mathrm{CF}_{3} \mathrm{CO}_{2} \mathrm{H}$; solvent $\mathrm{B}: 10 \% \mathrm{H}_{2} \mathrm{O}$ in $\mathrm{CH}_{3} \mathrm{CN}, 0.07 \%$ (v/v) $\mathrm{CF}_{3} \mathrm{CO}_{2} \mathrm{H}$ ), and the identity of purified samples was confirmed by electrospray mass spectrometry (Finnegan LCQ-Duo). All peptides are C-terminally amidated and N-terminally acetylated; each contains an acetamidobenzoate group on the sidechain nitrogen of a solventexposed lysine as a spectroscopic label.

CD Spectroscopy. All experiments were performed on an Aviv model 202 circular dichroism spectrometer, equipped with a Microlab 500 series automated titration assembly. Sample concentrations were measured by UV absorbance of the acetamidobenzoate label at $270 \mathrm{~nm}$. Wavelength data are the average of three scans from 250 to $200 \mathrm{~nm}$ in $1 \mathrm{~nm}$ steps. Thermal denaturation experiments at $222 \mathrm{~nm}$ were run from $0^{\circ}$ to $90^{\circ} \mathrm{C}$ in two-degree steps, at a twodegrees/minute rate of increase with one-minute equilibration and data averaging at each temperature. $T_{m}$ values were obtained from minima of the first derivative of $\theta$ vs. 1/T plots. ${ }^{2}$ Guanidinium titrations were performed using the automated titration assembly. The signal at $222 \mathrm{~nm}$ was recorded for solutions of constant peptide concentration with guanidine hydrochloride concentrations varied from 0 to 3M. Data were collected for one minute at each step, with ten-minute equilibration times (solutions were stirred during equilibration but not data collection).

Analytical Ultracentrifugation. Sedimentation equilibrium experiments were performed using a Beckman XL-I analytical ultracentrifuge equipped with an An60-Ti rotor. Data were collected using $12 \mathrm{~mm}$ path length six-sector centerpieces at $270 \mathrm{~nm}$. Samples were dialyzed against the reference buffer at $4^{\circ} \mathrm{C}$ overnight. Data were collected at 38,000 and 48,000 r.p.m. at concentrations spanning 17-55 $\mu \mathrm{M}$. Samples were equilibrated at 38,000 r.p.m. for 16 hours, followed by collection of two scans four hours apart. The speed was then increased to 48,000 r.p.m., followed by a 16 hour equilibration, and collection of two scans four hours apart, as before. Each scan consisted of 10 replicates at $0.002 \mathrm{~cm}$ radial steps. Solvent densities and partial molar volumes were calculated in the manner prescribed by Laue. ${ }^{3}$ Data were analyzed using Origin and fit to ideal single-species models.

(1) Schnöelzer, M.; Alewood, P.; Jones, A.; Alewood, D.; Kent, S. B. H. Int. J. Pept. Protein Res. 1992, 40, 180-193.

(2) Cantor, C. R.; Schimmel, P. R. Biophysical Chemistry of Macromolecules, Pt. 3: The Behavior of Biological Macromolecules; W. H. Freeman: New York, NY, 1980, p.1132.

(3) Laue, T. M.; Shah, B. D.; Ridgeway, T. M.; Pelletier, S. L. in Analytical Ultracentrifugation in Biochemistry and Polymer Science; Harding, S. E., Rowe, A. J., Horton, J. C., Eds.; The Royal Society of Chemistry: Cambridge, 1992; pp 90-125. 


\section{Analytical Ultracentrifugation Details}

Table S-1. Relative Molecular Masses from Analytical Ultracentrifugation ${ }^{a}$

\begin{tabular}{|c|c|c|c|}
\hline Sample & & $\mathrm{MW}_{\text {obs }} 38 \mathrm{krpm}$ & $\mathrm{MW}_{\text {obs }} 48 \mathrm{krpm}$ \\
\hline \multicolumn{4}{|l|}{$F_{9}: F_{16}: F_{23}$} \\
\hline & $17 \mu \mathrm{M}$ & 10566 & 10278 \\
\hline & $33 \mu \mathrm{M}$ & 11014 & 11042 \\
\hline & $55 \mu \mathrm{M}$ & 11593 & -- \\
\hline & average & \multicolumn{2}{|c|}{$\begin{array}{l}10898 \\
11535\end{array}$} \\
\hline & calc. (trimer) & & \\
\hline \multicolumn{4}{|l|}{$F_{9}: X_{16}: F_{23}$} \\
\hline & $17 \mu \mathrm{M}$ & 10832 & 10968 \\
\hline & $33 \mu \mathrm{M}$ & 11729 & 11104 \\
\hline & $55 \mu \mathrm{M}$ & 11915 & 11571 \\
\hline & average & \multirow{2}{*}{\multicolumn{2}{|c|}{$\begin{array}{l}11353 \\
11541\end{array}$}} \\
\hline & calc. (trimer) & & \\
\hline \multicolumn{4}{|l|}{$X_{9}: F_{16}: X_{23}$} \\
\hline & $17 \mu \mathrm{M}$ & 11729 & 11609 \\
\hline & $33 \mu \mathrm{M}$ & 11520 & 11108 \\
\hline & $55 \mu \mathrm{M}$ & -- & 12075 \\
\hline & average & \multirow{2}{*}{\multicolumn{2}{|c|}{$\begin{array}{l}11608 \\
11547\end{array}$}} \\
\hline & calc. (trimer) & & \\
\hline
\end{tabular}

${ }^{a}$ All samples were in aqueous buffer (10 mM phosphate buffer, $\left.150 \mathrm{mM} \mathrm{NaCl}, \mathrm{pH}=7.0\right)$. 

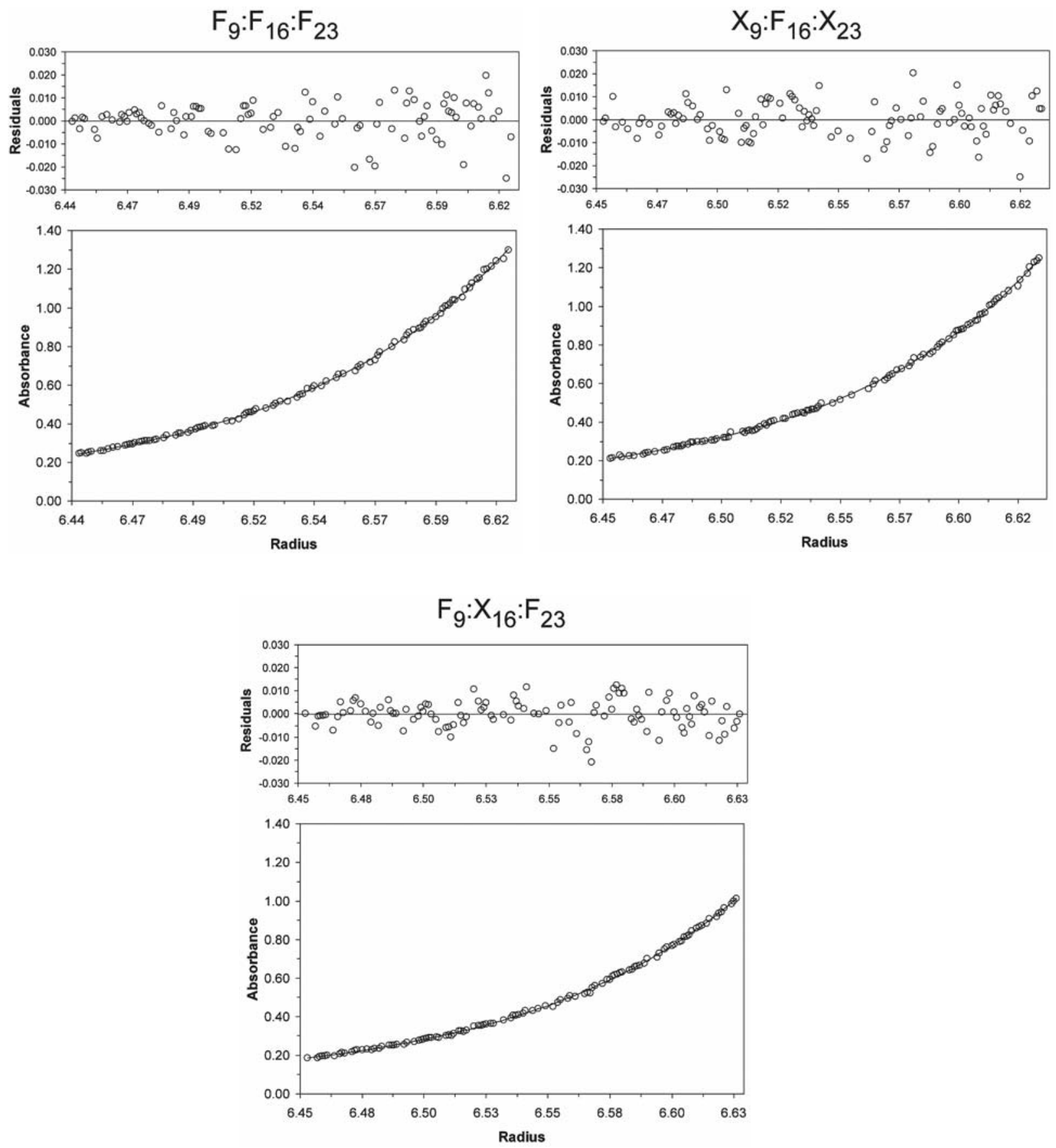

Figure S-1. Representative fits from ultracentrifugation. Data from $33 \mu \mathrm{M} 38 \mathrm{~K}$ runs. 


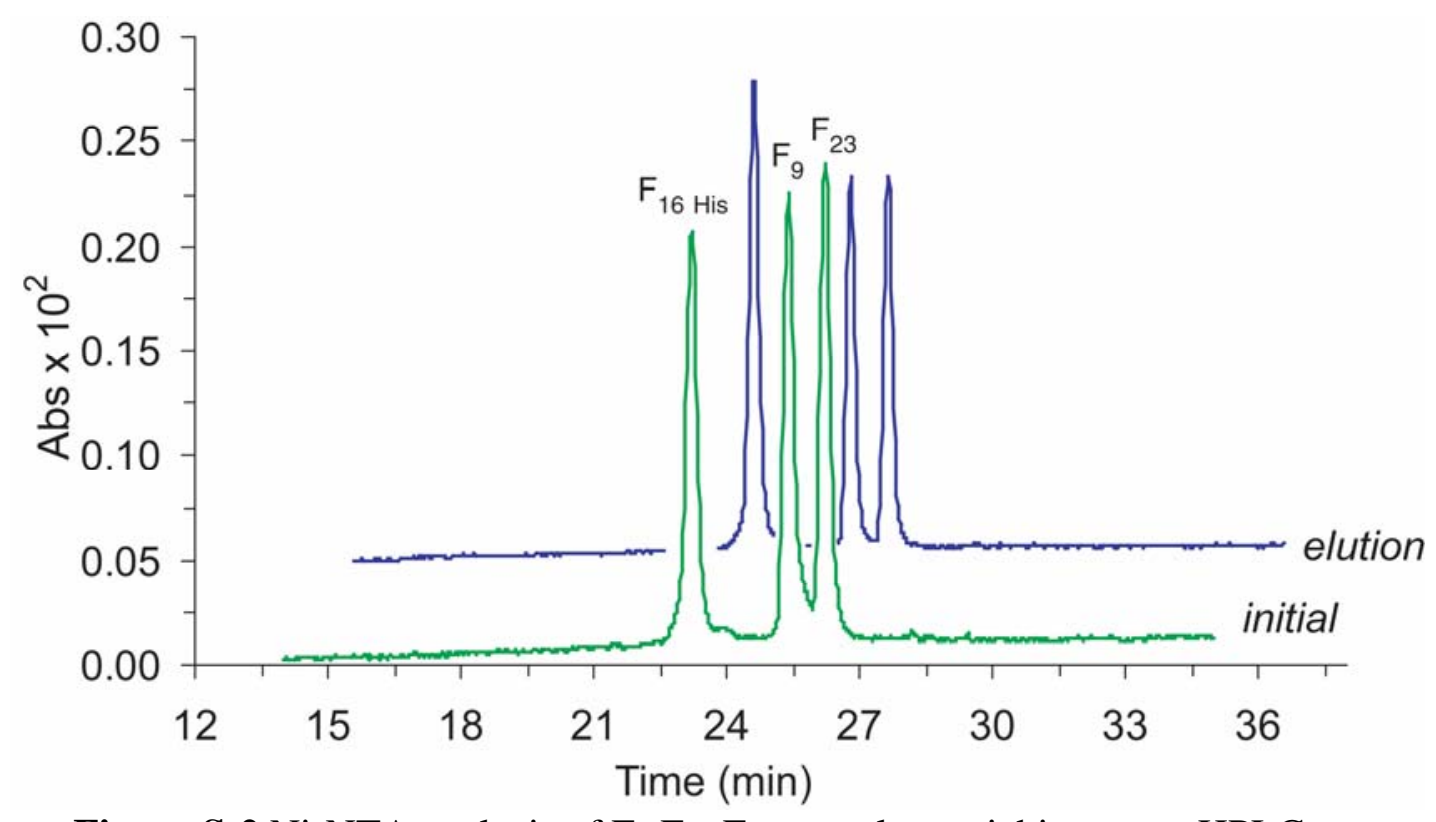

Figure S-2 Ni-NTA analysis of $\mathrm{F}_{9}: \mathrm{F}_{16}: \mathrm{F}_{23}$ complex stoichiometry. HPLC traces of initial 1:1:1 solution along with elution fraction demonstrating retention of one equivalent of each untagged peptide.
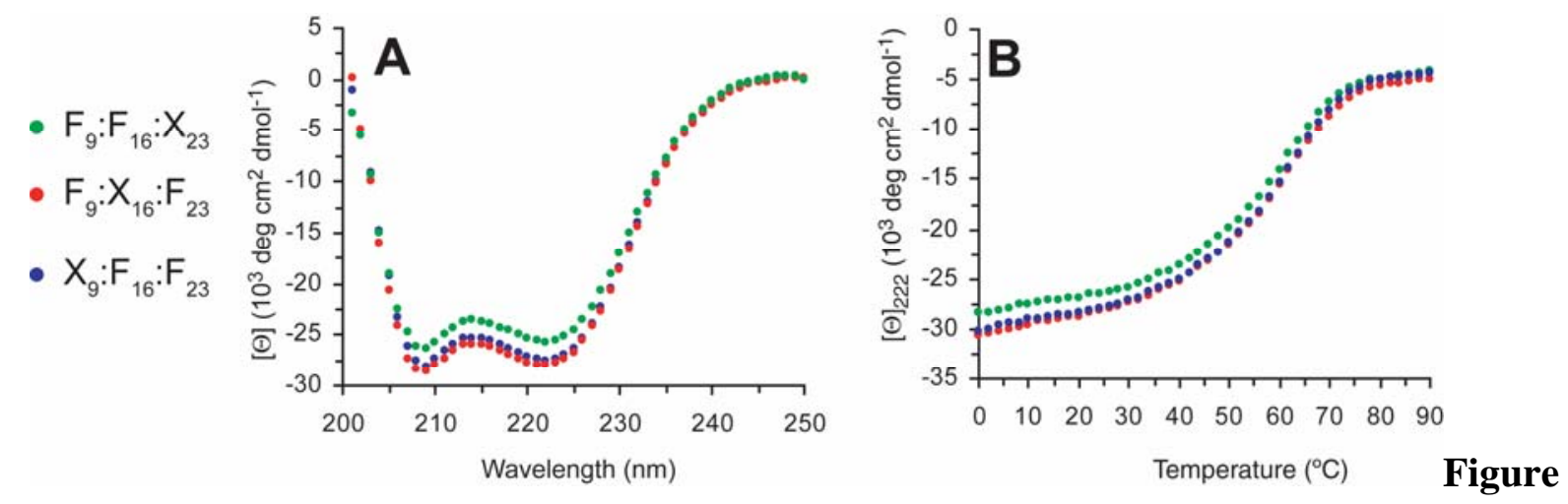

Figure S-3 Wavelength scan (A) and thermal denaturation (B) CD data for equimolar solutions of: $\mathrm{F}_{9}: \mathrm{F}_{16}: \mathrm{X}_{23}$ (green), $\mathrm{F}_{9}: \mathrm{X}_{16}: \mathrm{F}_{23}$ (red) and $\mathrm{X}_{9}: \mathrm{F}_{16}: \mathrm{F}_{23}$ (blue). All samples are $10 \mu \mathrm{M}$ total peptide in PBS buffer (10 mM phosphate $\mathrm{pH} 7.4,150 \mathrm{mM} \mathrm{NaCl}$ ). 

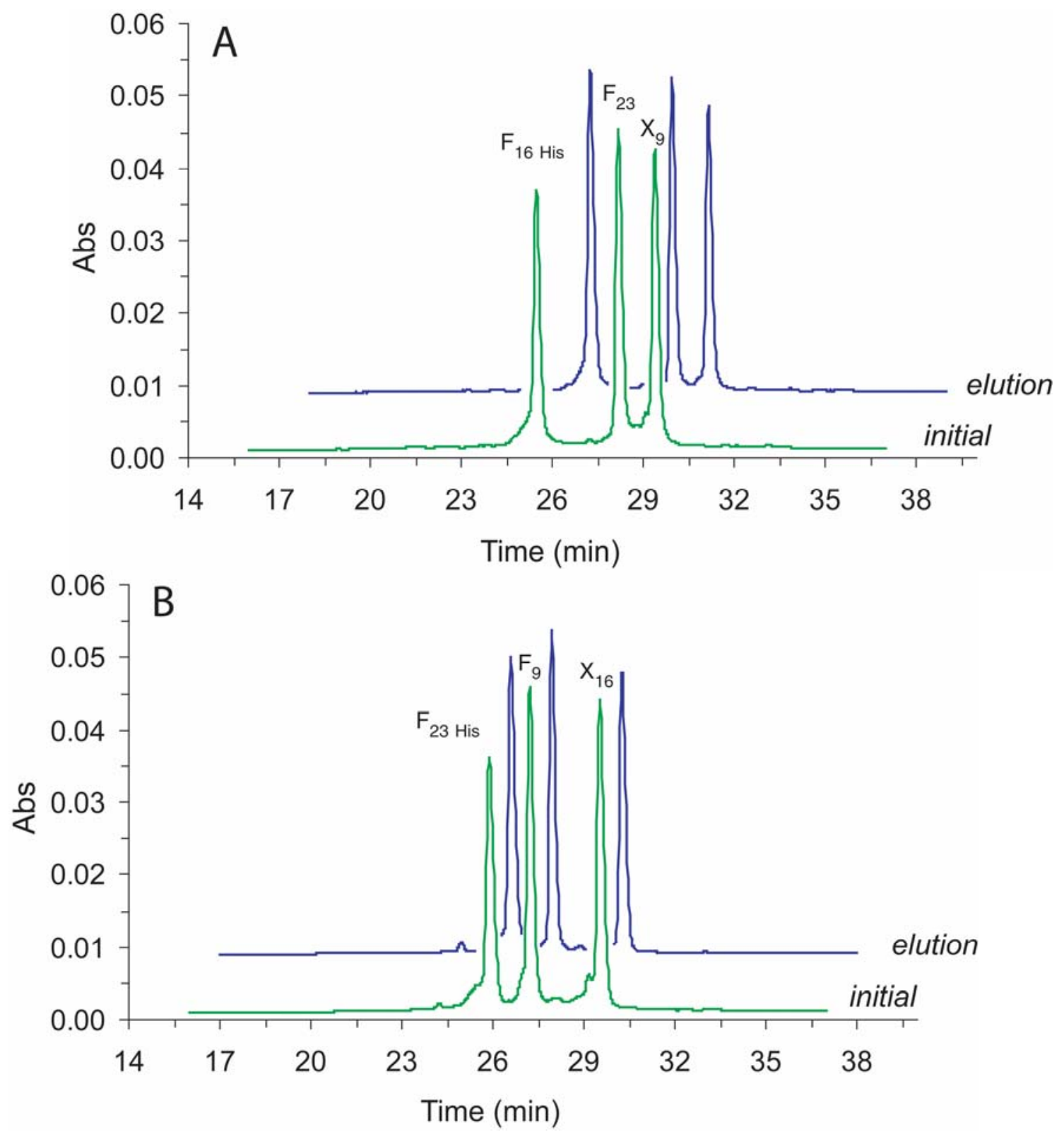

Figure S-4 Ni-NTA stoichiometry analysis of (A) $\mathrm{X}_{9}: \mathrm{F}_{16}: \mathrm{F}_{23}$ and (B) $\mathrm{F}_{9}: \mathrm{X}_{16}: \mathrm{F}_{23}$ complexes. HPLC traces demonstrate comparable retention of binding partners in each case. 


\section{Guanidine Denaturation Fit:}

Guanidine denaturation profiles were obtained on an Aviv model 202 circular dichroism spectrometer equipped with a Microlab 500 series titrator. A $10 \mu \mathrm{M}$ solution of peptide in PBS buffer (10mM Phosphate, $150 \mathrm{mM} \mathrm{NaCl}, \mathrm{pH}=7.4)$ was titrated with a second solution identical to the first but containing $6 \mathrm{M} \mathrm{GdnHCl}$. The raw data were converted to mean residue elipticity (MRE) and fit using the model outlined below.

Observed MRE values ( $\left.\theta_{\mathrm{obs}}\right)$ were fit assuming that folded and unfolded baselines are linear functions of denaturant concentration:

$$
\theta_{o b s}=f_{u}\left(\theta_{u}+a[G d n H C l]\right)+\left(1-f_{u}\right)\left(\theta_{f}+b[G d n H C l]\right)
$$

where $f_{u}=$ fraction unfolded, $\theta_{u}$ and $\theta_{f}$ are MREs of unfolded and folded peptides, and $a$ and $b$ are parameters describing the guanidine dependence of the observed unfolded and folded baselines. The fraction unfolded is calculated according to equation (2), assuming a monomertrimer equilibrium with equilibrium constant $K_{\text {unf }}$.

$$
f_{u}=\sqrt[3]{k\left(\frac{1}{2}+\frac{\sqrt{3} \sqrt{4 k+27}}{18}\right)}-\frac{1}{3} \frac{k}{\sqrt[3]{\frac{1}{2}+\frac{\sqrt{3} \sqrt{4 k+27}}{18}}}
$$

where:

$$
k=\frac{K_{u n f}}{27 C^{2} \text { tot }}
$$

and $\mathrm{C}_{\text {tot }}=$ [trimer $]=1 / 3$ [total peptide]. ${ }^{4}$ The equilibrium constant, in turn, is calculated from the observed unfolding energy, assuming a linear extrapolation model in which the true unfolding energy $\left(\Delta G_{H 2 O}\right)$ is assumed to be a linear function of the observed value and the denaturant concentration (equation 4$){ }^{5}$

$$
K_{\text {unf }}=e^{\frac{-\Delta \mathrm{GH}_{2} \mathrm{O}}{R T}} \quad \Delta G_{\mathrm{H}_{2} \mathrm{O}}=\Delta G_{\text {obs }}+m[\mathrm{GdnHCl}]
$$

The observed data were fit using this model and a non-linear least squares fit, with $\Delta G_{H 2 O}, \theta_{u}, \theta_{f}$, $a, b$, and $m$ as the parameters, employing a Microsoft Excel macro. ${ }^{6}$ Error estimates were calculated according to another macro by de Levie. ${ }^{7}$

(4) Jelesarov, I; Lu, M. J. Mol. Biol., 2001, 307, 637-656, and references therein.

(5) (a) Santoro, M. M.; Bolen, D. W. Biochemistry 1988, 27, 8063-8068. (b) Becktel, W. J.; Schellman, J. A.

Biopolymers 1987, 26, 1859-1877.

(4) Harris, D. C. J. Chem. Educ. 1998, 75, 119-121.

(7) De Levie, R. Journal of Chemical Education 1999, 76, 1594-1598. 